\title{
Oral Rehabilitation of a Female Child with Vitamin D-dependent Rickets Type II A: A Case Report
}

\author{
Nagarajan S ${ }^{1}$, Sanjeev Singh ${ }^{2}$, Aditi Kapur ${ }^{3}$, Ashima Goyal $^{4}$
}

\begin{abstract}
Vitamin D-dependent rickets (VDDR) describes a group of genetic disorders that are characterized by early-onset rickets due to the inability to maintain adequate concentrations of active forms of vitamin D or a failure to respond fully to activated vitamin $\mathrm{D}$. The prevalence rate is usually reported to be around 1:20,000. The oral manifestation includes dentin defects, unusually large pulp chambers, and enlarged pulp horns, hypoplastic enamel which is mostly seen in primary teeth than in permanent teeth. The present case report of VDDR in an 8.5-year-old female child highlights the clinical and radiographic features of the oral cavity along with the prosthetic rehabilitation to restore her stomatognathic functions. Keywords: Child, Hypophosphatemia, Prosthetic rehabilitation, Rickets, Vitamin D.

Journal of Postgraduate Medicine, Education and Research (2022): 10.5005/jp-journals-10028-1561
\end{abstract}

\section{INTRODUCTION}

Defects in vitamin $D$ responsiveness were first identified by Prader et al. in 1961, characterized by hypocalcemia and defective bone mineralization, not responsive to conventional vitamin $\mathrm{D}$ doses, leading to an independent diagnosis as "vitamin D-dependent rickets" (VDDR). ${ }^{1}$ It is a group of genetic disorders that are characterized by earlyonset rickets due to the inability to maintain adequate concentrations of active forms of vitamin $D$ or a failure to respond fully to activated vitamin $D$ and have shown a lifelong "dependency" on vitamin D replacement therapy. There are three types of this entity with two subtypes in type I and type II VDDR (Table 1). Vitamin D-dependent rickets type II A (VDDR IIA) occurs due to autosomal recessive mutations of the vitamin $D$ receptor (VDR) gene causing failure in responding to activated vitamin $\mathrm{D}$, with rapidly progressing rachitic bone changes, hypocalcemia, secondary hyperparathyroidism, and alopecia. The clinical syndrome is evident in the second half of the first year of life and features include attenuation of growth, bowing of bones, positive Chvostek, cranial bossing, frequent fractures resulting in severe motor dysfunction and waddling gait. The occurrence of alopecia with varying severity is one of the distinguishing features of this type. It is rarely associated with muscle weakness, bone pain and grand mal seizure. The severity of disease depends on the type of mutation occurring in VDR gene. The present case will highlight the clinical manifestations and prosthetic oral rehabilitation of 8.5 years old female child affected by type II A vitamin D-dependent rickets.

\section{Case Description}

A female patient of 8.5 years was referred to the Outpatient Unit of Pedodontics and Preventive Dentistry from the Advanced Paediatric Centre of our institute where she was getting treated for vitamin D-dependent Rickets type IIA. She was the eldest child whose parents had a nonconsanguineous marriage and was found to be normal without any deformities at birth. Between the patient's two siblings, a 2-year-old girl presented with the only sign of complete hair loss in the scalp, sparse eyebrows, eyelashes, and a 5-year-old brother with no dental and skeletal abnormalities except dental caries. The clinical manifestations

\begin{abstract}
${ }^{1-4}$ Oral Health Sciences Centre, PGIMER, Chandigarh, India
Corresponding Author: Sanjeev Singh, Oral Health Sciences Centre, PGIMER, Chandigarh, India, Phone: +91 9780554348, e-mail: san.bajaj88@gmail.com

How to cite this article: Nagarajan S, Singh S, Kapur A, et al. Oral Rehabilitation of a Female Child with Vitamin D-dependent Rickets Type II A: A Case Report. J Postgrad Med Edu Res 2022;56(1):47-50.

Source of support: Nil

Conflict of interest: None
\end{abstract}

of the two affected siblings were tabulated in Table 2. The family pedigree was also drawn for the family and it is illustrated in Figure 1. The patient was admitted in the Advanced Paediatric Centre after an episode of tightening of bilateral upper limbs two days earlier, which lasted for 30 minutes. On general examination the patient had bent legs which were noticed by parents since 1.5 years of age and had given a history of progressive bowing of bilateral lower limbs since 2 years, widening of wrists and ankles noticed since 1.5 years of age, and diffuse hair loss at the age of 3 months along with early shedding of teeth. However, parents did not give any history of any previous medical consultation for the above developmental defects till then. The patient also had bowing of bilateral upper and lower extremities (genu valgum) with anterior bowing in the tibia of left leg, widening of bilateral ankles and wrist, prominent clavicles with protrusion of mesial ends. Extraoral features noted were frontal bossing, broad depressed nasal bridge, and complete hair loss in the scalp (alopecia), sparse eyebrow, and eyelashes (Fig. 2).

On intraoral examination, the patient had mixed dentition with multiple early exfoliated primary teeth. Mandibular first molars were fully erupted, however upper molars were unerupted. The upper right central incisor was yet to erupt when compared to the left counterpart which was fully erupted. Similarly, the eruption status of the lower right lateral incisor lagged compared to the left counterpart. Pitting type of enamel hypoplasia was noted on the labial surface of the upper left central incisor and also in occlusal one-third of bilateral mandibular first molars with 
Table 1: Different types of vitamin D-dependent rickets along with subtypes

\begin{tabular}{|c|c|c|}
\hline S. No & Types & Explanation \\
\hline 1 & Type IA & $\begin{array}{c}\text { Mutations in the CYP27B1 gene on chromosome } \\
12 \text { q13.3 that encodes } 25 \text {-hydroxyvitamin } \\
\text { D3-1a-hydroxylase. }\end{array}$ \\
\hline 2 & Type IB & $\begin{array}{l}\text { Mutations in CYP2R1 that decrease expression or } \\
\text { function of the principal } 25 \text {-hydroxylase. }\end{array}$ \\
\hline 3 & Type IIA & $\begin{array}{l}\text { Biallelic loss-of-function mutations in the gene } \\
\text { encoding the vitamin } D \text { receptor on chromosome } \\
12 q 13.11 .\end{array}$ \\
\hline 4 & Type IIB & $\begin{array}{c}\text { Overexpression of a nuclear protein that } \\
\text { specifically interacts with a DNA response } \\
\text { element that binds retinoid X receptor-VDR } \\
\text { heterodimers. }\end{array}$ \\
\hline 5 & Type III & Increased inactivation of vitamin D metabolites. \\
\hline
\end{tabular}

Table 2: Clinical findings of two siblings with vitamin D-dependent rickets type II A

\begin{tabular}{|c|c|c|}
\hline Characteristics & Patient 1 & Patient 2 \\
\hline Age & 8 yrs. 3 months & $2 \mathrm{yrs}$ \\
\hline Sex & Female & Male \\
\hline Sequence of birth & First child & Third child \\
\hline Weight & 13.9 kg & \\
\hline Height & $100 \mathrm{~cm}$ & \\
\hline BMI & 13.9 & \\
\hline Head circumference & $50 \mathrm{~cm}$ & \\
\hline $\begin{array}{l}\text { Physical and facial features: } \\
\text { - Prominent forehead } \\
\text { - Depressed nasal bridge } \\
\text { - Prominent chin } \\
\text { - Protuberant abdomen }\end{array}$ & $\begin{array}{l}\checkmark \\
\checkmark \\
\checkmark \\
\checkmark\end{array}$ & $\times$ \\
\hline $\begin{array}{l}\text { Skeletal features: } \\
\text { - Bowing of B/L legs (Genu Valgum) } \\
\text { - Anterior bowing of tibia in left leg } \\
\text { - Widening of ankles } \\
\text { - Bowing of B/L hands } \\
\text { - Wrist widening } \\
\text { - Prominent clavicles with protrusion } \\
\text { of mesial ends }\end{array}$ & $\begin{array}{l}\checkmark \\
\checkmark \\
\checkmark \\
\checkmark \\
\checkmark \\
\checkmark\end{array}$ & $\begin{array}{l}\times \\
\times \\
\times\end{array}$ \\
\hline $\begin{array}{l}\text { Dermatologic features: } \\
\text { - Sparse eyelash } \\
\text { - Sparse eyebrows } \\
\text { - Alopecia }\end{array}$ & $\begin{array}{l}\checkmark \\
\checkmark \\
\checkmark\end{array}$ & \\
\hline $\begin{array}{l}\text { Central nervous system features: } \\
\text { - Raised intracranial pressure }\end{array}$ & $\checkmark$ & \\
\hline $\begin{array}{l}\text { Hematologic features: } \\
\text { - Anemia } \\
\text { - Thrombocytopenia } \\
\text { - Neutropenia } \\
\text { - Lymphopenia }\end{array}$ & & \\
\hline
\end{tabular}

distorted crown morphology, showing deep occlusal fissures (Fig. 3). An orthopantomogram (OPG) showed teeth with enlarged pulp chambers with pulp horns extending to dentinoenamel junction. Roots were shorter when compared with the length of root development seen in normal children of the same age (Fig. 4). An intraoral periapical radiograph showed thickening of lamina dura.

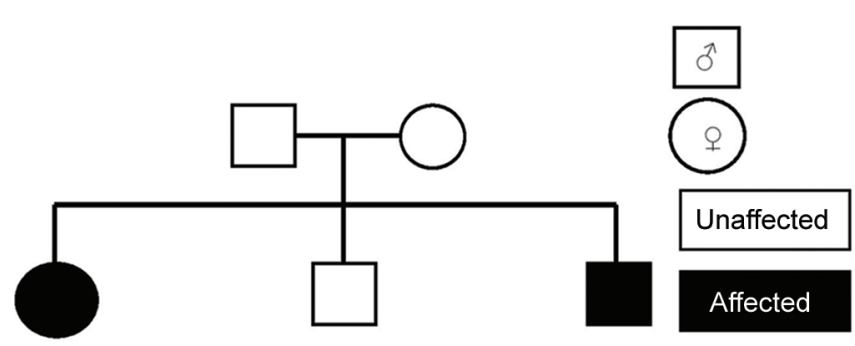

Fig. 1: Family pedigree showing affected and unaffected members

\section{Treatment Plan}

- Oral prophylaxis

- Restoration of carious teeth

- Pit and fissure application on erupted first permanent molars

- Prosthetic rehabilitation with upper and lower partial dentures.

\section{Treatment Procedure}

The patient received oral prophylaxis followed by composite restorations in carious deciduous upper canines. Pit and fissure sealants placement were done for the deep fissures on the occlusal surface of lower right and left first permanent molars. The composite aesthetic restoration was done for managing the pitted hypoplasia on incisal one-third of left permanent central incisor, followed by topical fluoride varnish application using Fluoritop SR ICPA ${ }^{\oplus}(22,600$ PPM). The patient was advised not to eat or brush for 4 hours after varnish application. To improve the chewing efficiency of the child, prosthetic rehabilitation with removable partial denture was planned in both upper and lower arch, for which upper and lower alginate impressions were made and poured with type II dental stone. A study cast was retrieved and duplicated to form a working cast. Acrylic baseplate was fabricated, on which occlusal rim was made followed by bite registration. The bite was articulated in a hinge articulator and to achieve retention, $\mathrm{C}$-clasps were given around lower right and left permanent first molars. Since the incisors were erupting, the treatment option of complete overdenture was ruled out. So, to facilitate the eruption of teeth, a box-shaped space was created in the upper incisor region. This design also aids in indirect retention of the denture. The minor changes were also carried out during wax try-in after taking a bite registration with syringe material and occlusion was corrected (Figs 5 A and B ). The acrylic resin was heat-cured, finished, polished, and the final dentures were inserted for the patient (Fig. 5C). The child was comfortable with the denture and able to perform her stomatognathic functions and showed a positive response toward the treatment in terms of functions and aesthetics.

\section{Follow-up}

The patient was kept on a 6-month recall for periodic fluoride application and to monitor eruption status of the teeth and adjustments needed indenture, if any. Emphasis was put on the prevention of dental caries by progressive reinforcement of the importance of oral hygiene maintenance.

\section{Discussion}

In literature, eleven different mutations in the gene-encoding VDR have been reported. They affect either the C-terminal ligand-binding region or the $\mathrm{N}$-terminal DNA binding zinc-fingers sequences, 


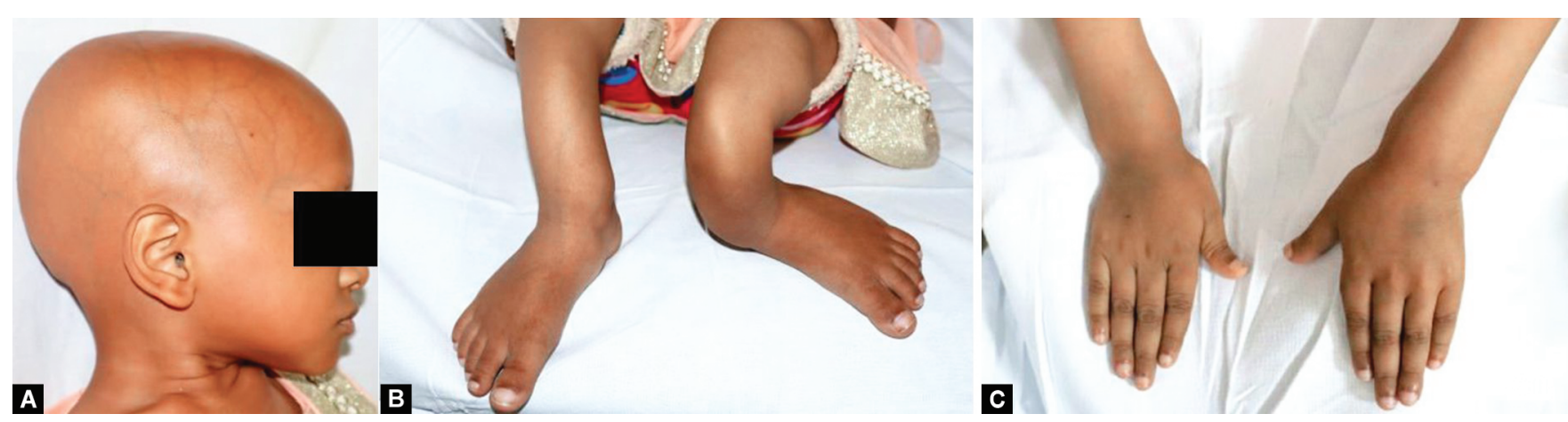

Figs $2 \mathrm{~A}$ to C: Clinical features of 8.5 years old female child (A) Facial image showing alopecia; (B) Bowing of B/L legs with anterior bowing of tibia in left leg; (C) Wrist widening

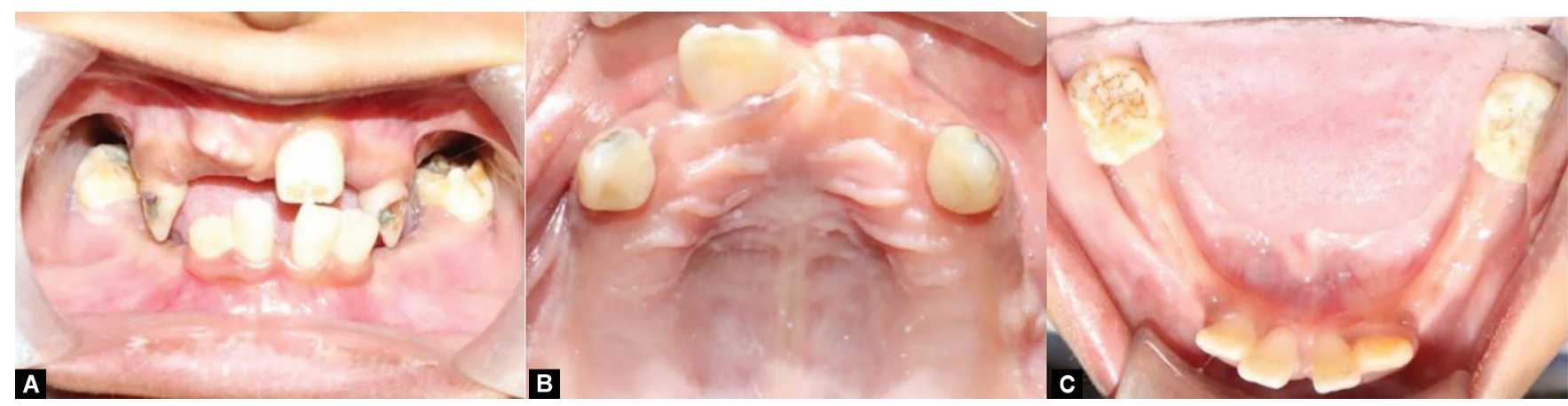

Figs 3A to C: Intraoral images of (A) Frontal view: enamel hypoplasia irt maxillary left central incisor; (B, C) Early exfoliation of deciduous teeth in the maxillary and mandibular arches

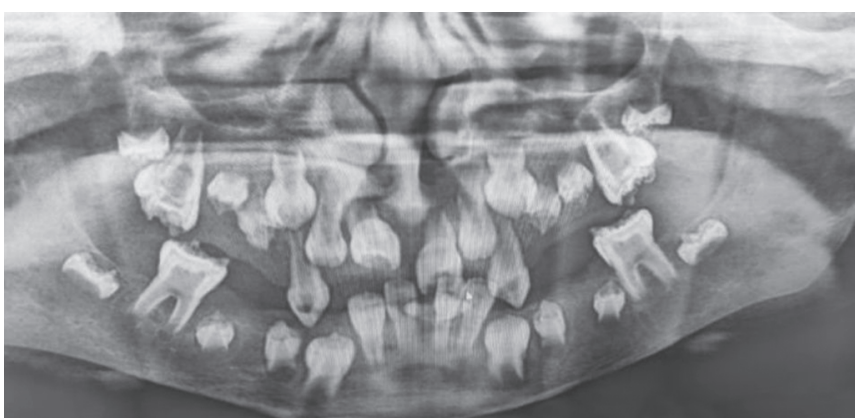

Fig. 4: Orthopantomogram of 8.5 years old female child showing early exfoliation and delayed development in permanent tooth buds

and the clinical manifestations vary according to the affected sequence. Management of the VDDR2 includes administering high doses of oral calcitriol (1-6 $\mu \mathrm{g} / \mathrm{kg} /$ day in two divided doses) and supplemental calcium (1-3 g/day) for mild to moderate cases.

Early exfoliation of primary teeth was noted in the present case which is not seen in any of the previous case reports on VDDR2. Delayed eruption of permanent teeth and dental caries in the primary dentition was seen in this patient and it was also reported by Hochberg et al. $^{2}$ However, dental caries was not seen in the case study reported by Sousa et al. ${ }^{3}$ Another reported finding is the attrition of newly erupted teeth frequently associated with periapical abscess as per Hillman et al. and Hochberg et al. ${ }^{2,4}$ This significant clinical oral finding of VDDR was explained by attrition of tooth, exposing the underlying dentin and facilitating the penetration of microorganisms through dentinal clefts, tubular defects, or voids in the calcified matrix of dentin. Abscesses related to attrition were not seen in the present case, perhaps due to relatively timely referral, emphasizing its importance. Additionally, enamel hypoplasia was noted in this patient and is also seen in case reports by Balsan et al., Souza et al., Hochberg et al., Chhonkar et al. ${ }^{2,3,5,6}$ The clinical appearance of hypoplastic molars resembles mulberry molars as mentioned by Chhonkar et al. ${ }^{6}$ The clinical appearance of the molars in the present case was not in concordance with Chhonkar et al.

Radiographically, the enlarged pulp chambers are the striking feature and cementum is seen to be affected along with dentin formation with thickened lamina dura (Balsam et al., Hochberg et al.). 2,5 Studies describing the molecular genetics behind this disease (Kato et al.) explain that complete loss of VDR function correlates with severity of disease expression (e.g., complete alopecia) and was supported by Seow et al. who have correlated the histologic grades of severity of dentin involvement with clinical grades. ${ }^{7,8}$ Good dental care for children with VDDR will likely help them to maintain good general health by preventing pain and improving their nutrition and aesthetic appearance and thereby improving their well-being. Proper dental referral from pediatricians is also mandatory to improve the overall quality of life.

Dentists should consider patient's general condition, physical disability, medical history, oral health and current therapeutic status. Dental care should include dietary counseling, plaque control, oral hygiene instructions, daily fluoride mouth rinses, or the use of fluoridated toothpaste, professional topical fluoride application, and sealants if necessary. Pit and fissure sealants are useful when the teeth are erupting, as they prevent the ingress of bacteria into enamel microfractures and the initiation of caries in deep pits and fissures. Restorative care with composite restoration and crowns is indicated for the management of carious teeth. Prophylactic placement of stainless-steel crown 


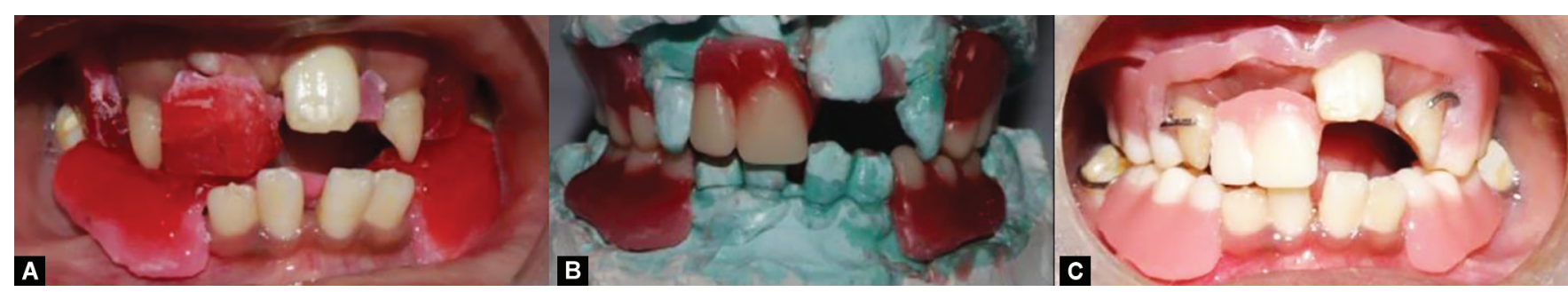

Figs 5A to C: (A) Bite registration; (B) Prosthetic rehabilitation showing wax try-in, teeth setting; (C) Denture insertion

in molars have been attempted (Chhonkar et al.) however, the risk of pulp exposure during tooth preparation should also be considered. ${ }^{6}$ In case of gingival/periapical abscess associated with attrited teeth showing no frank cavitation or no history of trauma, pulpectomy should be done followed by placement of full-coverage crowns. Partial dentures can be placed to maintain space, improve mastication, esthetic, and speech issues related to agenesis, as were done in the present case. Although malocclusion is correctable with orthodontic treatment, tooth movement is contraindicated due to short and thin roots and poorly formed cementum. ${ }^{9}$ Extractions should be carried out carefully since there is a great risk of bone fracture as they are brittle and precautions must be taken to avoid bacteremia during scaling, surgery, and endodontic treatment. ${ }^{10}$

\section{Conclusion}

VDDR patients require professional dental care likewise anticipatory guidance, topical fluoride varnish application, maintenance of oral hygiene, timely restorative care and prosthetic rehabilitation. Early referral to the dentist will help in reducing the chances of progression of dental infections, making treatment less complicated, and also help to improve the overall well-being of the child.

\section{References}

1. Prader A, Illig R, Heierli E. Vitamin-D-resisteuten rachitis mit hypocalcaemie und autosomal-dominantem Erbgang: die hereditaere PsuedoMangelrachitis. Helvetica Paediatrica Acta 1961;16:452-468.
2. Hochberg Z. Vitamin-D-dependent rickets type 2. Horm Res 2002;58(6):297-302. DOI: 10.1159/000066442. PMID: 12446995.

3. Jiménez-Sousa MÁ, Martínez I, Medrano LM, et al. Vitamin D in human immunodeficiency virus infection: influence on immunity and disease. Front Immunol 2018;12;9:458. DOI: 10.3389/fimmu.2018.00458

4. Hillmann G, Geurtsen W. Pathohistology of undecalcified primary teeth in vitamin D-resistant rickets: review and report of two cases. Oral Surg Oral Med Oral Pathol Oral Radiol Endod 1996;82(2):218-224. DOI: 10.1016/s1079-2104(96)80260-5

5. Balsan S, Garabedian M, Larchet M, et al. Long-term nocturnal calcium infusions can cure rickets and promote normal mineralization in hereditary resistance to 1,25-dihydroxyvitamin. D J Clin Invest 1986;77:1661-1667. DOI: 10.1172/JCI112483

6. Chhonkar A, Gupta A, Chaudhary P, et al. Oral rehabilitation of a pediatric patient with vitamin D-dependent rickets II: a rare case report. Int J Clin Pediatr Dent 2019;12(1):73-75. DOI: $10.5005 /$ jp-journals-10005-1586

7. Kato S. Genetic mutation in the human 25 -hydroxyvitamin $D_{3}$ 1alpha-hydroxylase gene causes vitamin D-dependent rickets type I. MolCell Endocrinol 1999;156:7-12.DOI: 10.1016/s0303-7207(99)00128-8

8. Seow WK, Romaniuk K, Sclavos S. Micromorphologic features of dentin in vitamin D-resistant rickets: correlation with clinical grading of severity. Pediatr Dent 1989;11(3):203-208.

9. Cohen S, Becker GL. Origin, diagnosis, and treatment of the dental manifestations of vitamin D-resistant rickets: a review of the literature and report of a case. J Am Dent Assoc 1976;92(1):120-129. DOI: 10.14219/jada.archive.1976.0327

10. Zambrano M, Nikitakis NG, et al. Oral and dental manifestations of vitamin D-dependent rickets type I: report of a pediatric case. Oral Surg Oral Med Oral Pathol Oral Radiol Endod 2003;95(6):705-709. DOI: $10.1067 /$ moe.2003.116 